\title{
Chapter 22 \\ Osteogenetic Effect of Low-Magnitude High-Frequency Loading and Parathyroid Hormone on Implant Interface in Osteoporosis
}

\author{
Aya Shibamoto, Toru Ogawa, Masayoshi Yokoyama, Joke Duyck, \\ Katleen Vandamme, Ignace Naert, and Keiichi Sasaki
}

\begin{abstract}
Osteoporosis could potentially complicate oral implant treatment because of disease-specific characteristics such as the abnormal bone condition, poor healing ability caused by bisphosphonates (BPs), and bisphosphonate-related osteonecrosis of the jaw (BRONJ). These problems must be resolved to ensure that oral implant treatment is successful in osteoporotic patients.

As a novel therapeutic option for increasing the success rate of oral implantation in patients with osteoporosis, we focused on parathyroid hormone (PTH) and lowmagnitude high-frequency (LMHF) loading. Compared to BPs, which inhibit osteoclastic bone resorption and suppress bone turnover, PTH stimulates osteoblastic bone formation and promotes bone turnover. Intermittent PTH administration is a new class of anabolic therapy for the treatment of severe osteoporosis. LMHF loading, which elicits a positive effect on skeleton, has been proposed as a nonpharmacological and adjunctive intervention in the treatment of osteoporosis. Previous investigation reported that both intermittent PTH administration and LMHF loading have an independent osteogenic effect on peri-implant bone healing and implant osseointegration. In addition, our recent study reveals their combined therapy acts locally and synergistically on peri-implant bone healing process, strengthening osseointegration.

Therefore, this can be a new therapeutic option for oral implant treatment in osteoporotic patients without any problems.
\end{abstract}

\footnotetext{
A. Shibamoto $\bullet$ T. Ogawa $(\bowtie) \bullet$ M. Yokoyama

Division of Advanced Prosthetic Dentistry, Tohoku University Graduate School of Dentistry,

4-1 Seiryo-machi, Aoba-ku, Sendai, Miyagi 980-8575, Japan

e-mail: ogat-thk@umin.ac.jp

J. Duyck $\bullet$ K. Vandamme $\bullet$ I. Naert

Department of Oral Health Sciences, Prosthetic Dentistry, BIOMAT - Biomaterials,

Katholieke Universiteit Leuven, Leuven, Belgium

K. Sasaki

Division of Advanced Prosthetic Dentistry, Tohoku University Graduate School of Dentistry,

4-1 Seiryo-machi, Aoba-ku, Sendai, Japan
} 
Keywords Oral implant • High-frequency loading • Parathyroid hormone • Osseointegration

\subsection{Background}

Oral implants are a well-accepted and predictable treatment option for the rehabilitation of partially and completely edentulous patients. The osseointegrated implants' success depends on the mechanical support of the host bone in achieving primary stability and the biological process of bone adaptation and regeneration in achieving secondary stability [1]. Nevertheless, the extended life expectancy in today's society has expanded the indications for oral implantation in elderly patients with systemic diseases.

Osteoporosis is a metabolic bone disorder characterized by low bone mass and microarchitectural deterioration of the bone, leading to enhanced bone fragility and a consequent increase in fracture risk [2]. Regardless of the disease characteristics, osteoporosis is not considered an absolute contraindication for oral implant treatment $[3,4]$. However, some studies have reported implant failure because of a lack of primary stability and difficulty in achieving osseointegration in patients with osteoporosis [5, 6]. In addition, bisphosphonates (BPs), which are antiresorptive agents and are widely used as the first-choice therapy for osteoporosis, could be a risk factor for implant failure. Kasai et al. [7] compared the success rate of oral implants placed in female patients taking oral BPs with a control group not taking BPs. The BP group had an $86 \%$ success rate, while the control group had a $95 \%$ success rate. BPs also are known to induce BP-related osteonecrosis of the jaw (BRONJ), a serious side effect in patients undergoing invasive oral surgery [8]. There are no universally accepted prevention or treatment protocols for BRONJ $[9,10]$.

Therefore, to treat osteoporotic patients with oral implants successfully, it is necessary to overcome problems associated with the characteristics of osteoporosis, BPs, and BRONJ. As a novel therapeutic option for increasing the success rate of oral implantation in patients with osteoporosis, we focused on teriparatide [hPTH(134)] and low-magnitude high-frequency (LMHF) loading. The aim of this review was to evaluate the single and combined effects of LMHF loading and PTH treatment on peri-implant bone healing and implant osseointegration in osteoporosis.

\subsection{Teriparatide [hPTH(1-34)]}

\subsubsection{PTH as a Therapy for Osteoporosis}

Teriparatide [hPTH(1-34)] is an analog of human parathyroid hormone (PTH) containing the amino acid sequence 1-34. It is a new class of anabolic agents acting on the skeleton and should be considered as an alternative to existing antiresorptive agents for the treatment of severe osteoporosis and intractable fractures [11]. Indeed, intermittent systemic administration of hPTH(1-34) reduces the risk of fractures 
$[12,13]$ by improving bone microarchitecture and enhancing overall bone mass [14, 15]. Black et al. [16] reported that $\mathrm{hPTH}(1-34)$ exceeded BPs in increasing bone mineral density. In contrast with BPs, which inhibit osteoclastic bone resorption and decrease the bone remodeling rate, PTH stimulates osteoblastic bone formation through an increase in the bone remodeling rate [17]. However, the clinical problems of PTH are as follows: PTH is significantly more expensive than antiresorptive agents [11], PTH is administered by subcutaneous injection [11], and the duration of administration is limited to $<2$ years based on the induction of osteosarcoma in a rat model of carcinogenicity $[18,19]$.

\subsubsection{Effect of Intermittent PTH Administration on Peri-implant Bone}

Recent studies have also reported that intermittent hPTH(1-34) administration promotes peri-implant bone healing in animal and clinical models [20-22]. Our present study also confirmed that intermittent $\mathrm{hPTH}(1-34)$ administration has a potent osteogenic capability in stimulating implant osseointegration in ovariectomized (OVX) rats as described in Sect. 30.4. Although there are clinical problems associated with PTH, replacement of BPs with PTH is expected to improve bone density and quality in surgical sites, promote peri-implant bone formation, and prevent the development of BRONJ.

\subsection{Low-Magnitude High-Frequency (LMHF) Loading}

\subsubsection{Effect of LMHF Loading on Skeletal Tissue}

LMHF loading, which is generally defined as an LM of $<1 g\left(1 g=9.98 \mathrm{~m} / \mathrm{s}^{2}\right)$ and HF of $20-90 \mathrm{~Hz}$, elicits a positive effect on the skeleton (Fig. 22.1) [23, 24]. Numerous studies have evidenced that LMHF loading, applied by means of wholebody vibration (WBV), stimulates bone formation and fracture healing [25-28]. WBV loading has already been used clinically as a nonpharmacological intervention in the treatment of osteoporosis [29-34].

\subsubsection{Effect of LMHF Loading on Peri-implant Bone}

Regarding titanium implant osseointegration, which has similarities with bone fracture healing, the coauthors' previous studies showed that LMHF loading has an osteogenetic effect on peri-implant bone [35-37]. In particular, Ogawa et al. [35, 38] confirmed that the specific parameters of a loading regimen, such as the 
Fig. 22.1 Osteogenetic effect of LMHF loading. Montages of photomicrographs of the proximal sheep femur used for static

histomorphometric evaluation after 1 year of exposure (20 min per day) to a $0.3 \mathrm{~g}, 30-\mathrm{Hz}$ mechanical stimulus. There was $32 \%$ more trabecular bone in the proximal femur of experimental animals (a) compared with age-matched controls (b) $(P<0.04)[23]$
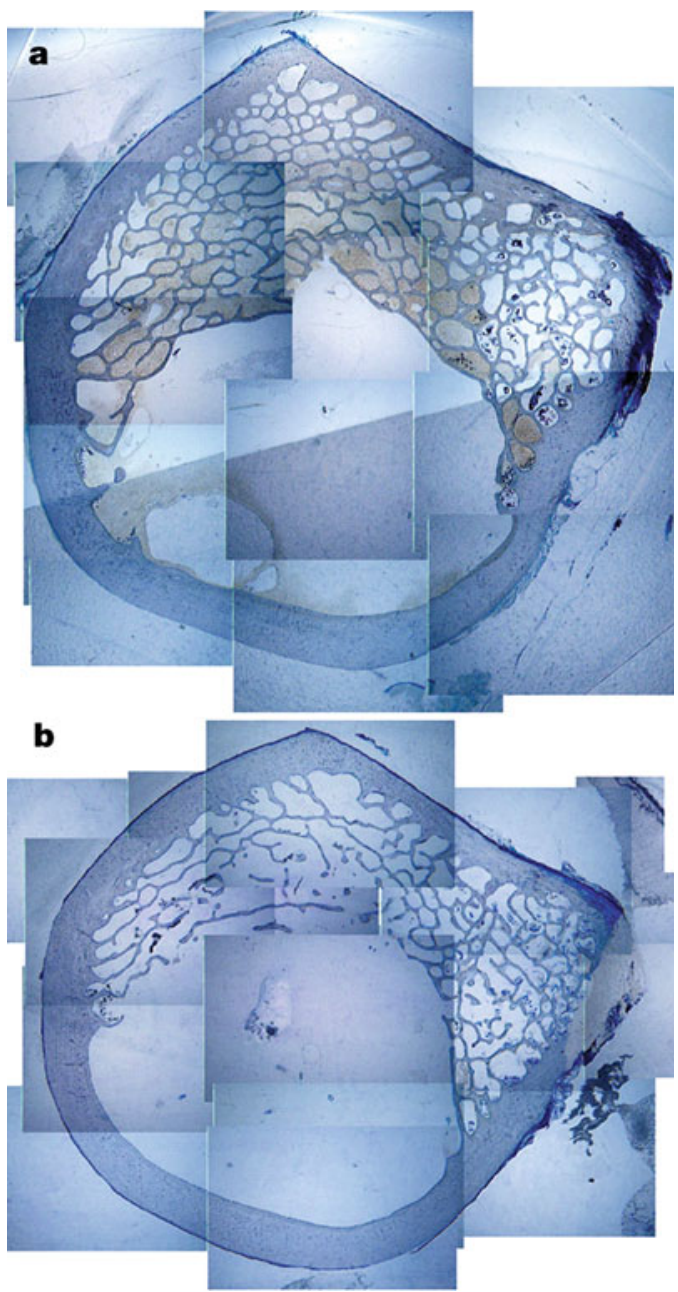

duration, session distribution, frequency, and amplitude of loading, play an important role in the impact of LMHF loading on the bone (Fig. 22.2). Additionally, the application of LMHF loading reportedly enhances bone-implant osseointegration in OVX rats [39-41], which was observed in our present study as described in Sect. 30.4 
Fig. 22.2 Effect of LMHF loading on peri-implant bone healing and implant osseointegration.

Representative images of the test (loaded) and control (unloaded) group from the 1-week healing period (a) and the 4-week healing period (b). Scale bars: $1 \mathrm{~mm}$. After 4 weeks of healing, the bone neoformation and cortical bone width were much greater in the test group than in the control [35]
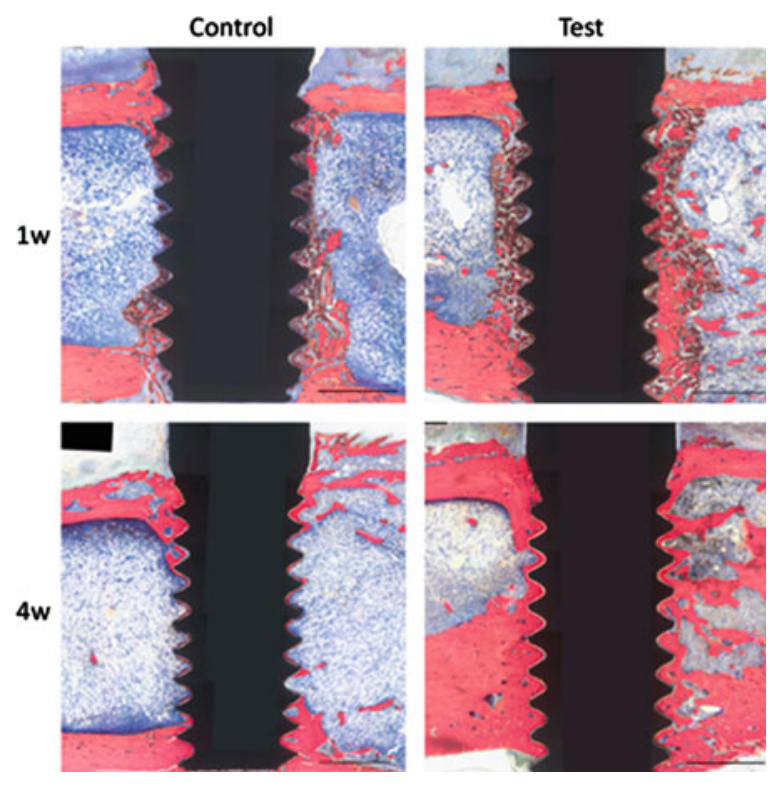

\subsection{Effect of LMHF Loading and Intermittent PTH on Peri-implant Bone}

Both LMHF loading and intermittent hPTH(1-34) administration have an independent osteogenic effect on peri-implant bone healing and implant osseointegration. However, there are no reports on the impact of their combined therapy on periimplant bone. It seems likely that combined therapy would act synergistically on the bone healing process and strengthen bone-implant osseointegration. Additionally, the potential synergistic effect may shorten the healing period, thereby relieving the clinical problems associated with PTH.

Our recent study compared the osteogenic impact of LMHF loading and intermittent hPTH(1-34) administration on peri-implant bone healing and implant osseointegration in an osteoporosis model and evaluated their combined effect on these processes. Thirteen-week-old ovariectomized rats $(n=88)$ were divided into three groups: each group of rats received PTH (40 $\mu \mathrm{g} / \mathrm{kg}, 5$ days/week), alendronate (15 $\mu \mathrm{g} / \mathrm{kg}, 2$ days/week), and saline (volume-matched vehicle control), respectively. After 3 weeks, a titanium implant was inserted in both tibiae. Again, each group was subdivided into two groups: with or without LMHF loading via whole-body vibration (WBV, $50 \mathrm{~Hz}$ at $0.5 \mathrm{~g}, 15 \mathrm{~min} /$ day, 5 days/week). The rats were sacrificed 1 or 4 weeks after implant installation. Peri-implant bone healing and implant osseointegration were assessed using removal torque tests (RT value) and micro-CT analyses (relative gray $(R G)$ value, water $=0$ and implant $=100$ ). The data were analyzed by three-factor ANOVA (loading, drug, healing period) followed with a Tukey-HSD test $(\alpha=0.05)$. RT value was significantly influenced by all three factors 
$(P<0.01)$. In particular for PTH-WBV group, these values were highest in all groups after 4 weeks of healing. In the cortical bone, RG value was significantly influenced by the loading $(P<0.01)$. In the trabecular bone, on the other hand, RG value was significantly influenced by the drug $(P<0.01)$. The $\mathrm{RG}$ values of the PTH-treated groups were significantly higher than those of other drug-treated groups $(P<0.01)$. The results reveal that LMHF loading and PTH act locally and synergistically on bone healing process, thereby strengthening implant osseointegration. Interestingly, a previous study reported that the combination of ALN and LMHF loading did not lead to a synergistic reaction influencing the bone healing response [41]. Similar to the present study, no obvious positive effect was found in the ALN and ALN+WBV groups. This might be because ALN inhibits osteoclastic bone activity, which is required in the process of bone adaptation and therefore of implant osseointegration. The results also indicate that PTH combined with LMHF loading has a bone-stimulating effect superior to that of ALN and LMHF loading.

\subsection{Conclusion}

There were four main findings in this review. In osteoporosis model:

- LMHF loading has an osteogenetic effect on the peri-implant bone.

- Intermittent hPTH(1-34) administration has a potent osteogenic capability in stimulating implant osseointegration.

- Two treatment modalities act locally on the bone healing process. The cortical bone was influenced by LMHF loading. The trabecular bone was influenced by PTH.

- The combined application of LMHF loading and PTH synergistically stimulates implant osseointegration. Additionally, PTH combined with LMHF loading has a bone-stimulating effect superior to that of ALN and LMHF loading.

Therefore, this can be a new therapeutic option for oral implant treatment in osteoporotic patients without problems such as failure of osseointegration, delayed healing, or BRONJ.

Conflicts of Interest The authors report no conflicts of interest.

\section{References}

1. Meredith N. Assessment of implant stability as a prognostic determinant. Int J Prosthodont. 1998;11(5):491-501.

2. Kanis JA. Assessment of fracture risk and its application to screening for postmenopausal osteoporosis: synopsis of a WHO report. WHO Study Group. Osteoporos Int. 1994;4(6):368-81. 
3. Hwang D, Wang HL. Medical contraindications to implant therapy: part I: absolute contraindications. Implant Dent. 2006;15(4):353-60. doi:10.1097/01.id.0000247855.75691.03.

4. Hwang D, Wang HL. Medical contraindications to implant therapy: part II: relative contraindications. Implant Dent. 2007;16(1):13-23. doi:10.1097/ID.0b013e31803276c8.

5. Alsaadi G, Quirynen M, Komarek A, van Steenberghe D. Impact of local and systemic factors on the incidence of oral implant failures, up to abutment connection. J Clin Periodontol. 2007;34(7):610-7. doi:10.1111/j.1600-051X.2007.01077.x.

6. Ozawa S, Ogawa T, Iida K, Sukotjo C, Hasegawa H, Nishimura RD, et al. Ovariectomy hinders the early stage of bone-implant integration: histomorphometric, biomechanical, and molecular analyses. Bone. 2002;30(1):137-43.

7. Kasai T, Pogrel MA, Hossaini M. The prognosis for dental implants placed in patients taking oral bisphosphonates. J Calif Dent Assoc. 2009;37(1):39-42.

8. Russell RG, Xia Z, Dunford JE, Oppermann U, Kwaasi A, Hulley PA, et al. Bisphosphonates: an update on mechanisms of action and how these relate to clinical efficacy. Ann N Y Acad Sci. 2007;1117:209-57. doi:10.1196/annals.1402.089.

9. Khan AA, Morrison A, Hanley DA, Felsenberg D, McCauley LK, O'Ryan F, et al. Diagnosis and management of osteonecrosis of the jaw: a systematic review and international consensus. J Bone Miner Res. 2015;30(1):3-23. doi:10.1002/jbmr.2405.

10. Yoneda T, Hagino H, Sugimoto T, Ohta H, Takahashi S, Soen S, et al. Bisphosphonate-related osteonecrosis of the jaw: position paper from the Allied Task Force Committee of Japanese Society for Bone and Mineral Research, Japan Osteoporosis Society, Japanese Society of Periodontology, Japanese Society for Oral and Maxillofacial Radiology, and Japanese Society of Oral and Maxillofacial Surgeons. J Bone Miner Metab. 2010;28(4):365-83. doi:10.1007/ s00774-010-0162-7.

11. Hodsman AB, Bauer DC, Dempster DW, Dian L, Hanley DA, Harris ST, et al. Parathyroid hormone and teriparatide for the treatment of osteoporosis: a review of the evidence and suggested guidelines for its use. Endocr Rev. 2005;26(5):688-703. doi:10.1210/er.2004-0006.

12. Neer RM, Arnaud CD, Zanchetta JR, Prince R, Gaich GA, Reginster JY, et al. Effect of parathyroid hormone (1-34) on fractures and bone mineral density in postmenopausal women with osteoporosis. N Engl J Med. 2001;344(19):1434-41. doi:10.1056/nejm200105103441904.

13. Aspenberg P, Genant HK, Johansson T, Nino AJ, See K, Krohn K, et al. Teriparatide for acceleration of fracture repair in humans: a prospective, randomized, double-blind study of 102 postmenopausal women with distal radial fractures. J Bone Miner Res. 2010;25(2):404-14. doi:10.1359/jbmr.090731.

14. Hodsman AB, Kisiel M, Adachi JD, Fraher LJ, Watson PH. Histomorphometric evidence for increased bone turnover without change in cortical thickness or porosity after 2 years of cyclical hPTH(1-34) therapy in women with severe osteoporosis. Bone. 2000;27(2):311-8.

15. Jiang Y, Zhao JJ, Mitlak BH, Wang O, Genant HK, Eriksen EF. Recombinant human parathyroid hormone (1-34) [teriparatide] improves both cortical and cancellous bone structure. J Bone Miner Res. 2003;18(11):1932-41. doi:10.1359/jbmr.2003.18.11.1932.

16. Black DM, Greenspan SL, Ensrud KE, Palermo L, McGowan JA, Lang TF, et al. The effects of parathyroid hormone and alendronate alone or in combination in postmenopausal osteoporosis. N Engl J Med. 2003;349(13):1207-15. doi:10.1056/NEJMoa031975.

17. Rosen CJ, Bilezikian JP. Clinical review 123: anabolic therapy for osteoporosis. J Clin Endocrinol Metab. 2001;86(3):957-64. doi:10.1210/jcem.86.3.7366.

18. Tashjian Jr AH, Chabner BA. Commentary on clinical safety of recombinant human parathyroid hormone 1-34 in the treatment of osteoporosis in men and postmenopausal women. J Bone Miner Res. 2002;17(7):1151-61. doi:10.1359/jbmr.2002.17.7.1151.

19. Vahle JL, Sato M, Long GG, Young JK, Francis PC, Engelhardt JA, et al. Skeletal changes in rats given daily subcutaneous injections of recombinant human parathyroid hormone (1-34) for 2 years and relevance to human safety. Toxicol Pathol. 2002;30(3):312-21.

20. Shirota T, Tashiro M, Ohno K, Yamaguchi A. Effect of intermittent parathyroid hormone (1-34) treatment on the bone response after placement of titanium implants into the tibia of ovariectomized rats. J Oral Maxillofac Surg. 2003;61(4):471-80. doi:10.1053/joms.2003.50093. 
21. Kuchler U, Luvizuto ER, Tangl S, Watzek G, Gruber R. Short-term teriparatide delivery and osseointegration: a clinical feasibility study. J Dent Res. 2011;90(8):1001-6. doi: $10.1177 / 0022034511407920$.

22. Almagro MI, Roman-Blas JA, Bellido M, Castaneda S, Cortez R, Herrero-Beaumont G. PTH [1-34] enhances bone response around titanium implants in a rabbit model of osteoporosis. Clin Oral Implants Res. 2013;24(9):1027-34. doi:10.1111/j.1600-0501.2012.02495.x.

23. Rubin C, Turner AS, Bain S, Mallinckrodt C, McLeod K. Anabolism. Low mechanical signals strengthen long bones. Nature. 2001;412(6847):603-4. doi:10.1038/35088122.

24. Judex S, Gupta S, Rubin C. Regulation of mechanical signals in bone. Orthod Craniofac Res. 2009;12(2):94-104. doi:10.1111/j.1601-6343.2009.01442.x.

25. Omar H, Shen G, Jones AS, Zoellner H, Petocz P, Darendeliler MA. Effect of low magnitude and high frequency mechanical stimuli on defects healing in cranial bones. J Oral Maxillofac Surg. 2008;66(6):1104-11. doi:10.1016/j.joms.2008.01.048.

26. Hwang SJ, Lublinsky S, Seo YK, Kim IS, Judex S. Extremely small-magnitude accelerations enhance bone regeneration: a preliminary study. Clin Orthop Relat Res. 2009;467(4):1083-91. doi:10.1007/s11999-008-0552-5.

27. Sehmisch S, Galal R, Kolios L, Tezval M, Dullin C, Zimmer S, et al. Effects of low-magnitude, high-frequency mechanical stimulation in the rat osteopenia model. Osteoporos Int. 2009;20(12):1999-2008. doi:10.1007/s00198-009-0892-3.

28. Shi HF, Cheung WH, Qin L, Leung AH, Leung KS. Low-magnitude high-frequency vibration treatment augments fracture healing in ovariectomy-induced osteoporotic bone. Bone. 2010;46(5):1299-305. doi:10.1016/j.bone.2009.11.028.

29. Russo CR, Lauretani F, Bandinelli S, Bartali B, Cavazzini C, Guralnik JM, et al. Highfrequency vibration training increases muscle power in postmenopausal women. Arch Phys Med Rehabil. 2003;84(12):1854-7.

30. Rubin C, Recker R, Cullen D, Ryaby J, McCabe J, McLeod K. Prevention of postmenopausal bone loss by a low-magnitude, high-frequency mechanical stimuli: a clinical trial assessing compliance, efficacy, and safety. J Bone Miner Res. 2004;19(3):343-51. doi:10.1359/ jbmr.0301251.

31. Verschueren SM, Roelants M, Delecluse C, Swinnen S, Vanderschueren D, Boonen S. Effect of 6-month whole body vibration training on hip density, muscle strength, and postural control in postmenopausal women: a randomized controlled pilot study. J Bone Miner Res. 2004;19(3):352-9. doi:10.1359/jbmr.0301245.

32. Iwamoto J, Takeda T, Sato Y, Uzawa M. Effect of whole-body vibration exercise on lumbar bone mineral density, bone turnover, and chronic back pain in post-menopausal osteoporotic women treated with alendronate. Aging Clin Exp Res. 2005;17(2):157-63.

33. Gusi N, Raimundo A, Leal A. Low-frequency vibratory exercise reduces the risk of bone fracture more than walking: a randomized controlled trial. BMC Musculoskelet Disord. 2006;7:92. doi:10.1186/1471-2474-7-92.

34. von Stengel S, Kemmler W, Engelke K, Kalender WA. Effects of whole body vibration on bone mineral density and falls: results of the randomized controlled ELVIS study with postmenopausal women. Osteoporos Int. 2011;22(1):317-25. doi:10.1007/s00198-010-1215-4.

35. Ogawa T, Possemiers T, Zhang X, Naert I, Chaudhari A, Sasaki K, et al. Influence of wholebody vibration time on peri-implant bone healing: a histomorphometrical animal study. J Clin Periodontol. 2011;38(2):180-5. doi:10.1111/j.1600-051X.2010.01637.x.

36. Ogawa T, Zhang X, Naert I, Vermaelen P, Deroose CM, Sasaki K, et al. The effect of wholebody vibration on peri-implant bone healing in rats. Clin Oral Implants Res. 2011;22(3):3027. doi:10.1111/j.1600-0501.2010.02020.x.

37. Zhang X, Torcasio A, Vandamme K, Ogawa T, van Lenthe GH, Naert I, et al. Enhancement of implant osseointegration by high-frequency low-magnitude loading. PLoS One. 2012;7(7), e40488. doi:10.1371/journal.pone.0040488.

38. Ogawa T, Vandamme K, Zhang X, Naert I, Possemiers T, Chaudhari A, et al. Stimulation of titanium implant osseointegration through high-frequency vibration loading is enhanced when applied at high acceleration. Calcif Tissue Int. 2014;95(5):467-75. doi:10.1007/ s00223-014-9896-x. 
39. Akca K, Sarac E, Baysal U, Fanuscu M, Chang TL, Cehreli M. Micro-morphologic changes around biophysically-stimulated titanium implants in ovariectomized rats. Head Face Med. 2007;3:28. doi:10.1186/1746-160X-3-28.

40. Chen B, Li Y, Xie D, Yang X. Low-magnitude high-frequency loading via whole body vibration enhances bone-implant osseointegration in ovariectomized rats. J Orthop Res. 2012;30(5):733-9. doi:10.1002/jor.22004.

41. Chatterjee M, Hatori K, Duyck J, Sasaki K, Naert I, Vandamme K. High-frequency loading positively impacts titanium implant osseointegration in impaired bone. Osteoporos Int. 2015;26(1):281-90. doi:10.1007/s00198-014-2824-0.

Open Access This chapter is distributed under the terms of the Creative Commons Attribution 4.0 International License (http://creativecommons.org/licenses/by/4.0/), which permits use, duplication, adaptation, distribution and reproduction in any medium or format, as long as you give appropriate credit to the original author(s) and the source, provide a link to the Creative Commons license and indicate if changes were made.

The images or other third party material in this chapter are included in the work's Creative Commons license, unless indicated otherwise in the credit line; if such material is not included in the work's Creative Commons license and the respective action is not permitted by statutory regulation, users will need to obtain permission from the license holder to duplicate, adapt or reproduce the material. 